
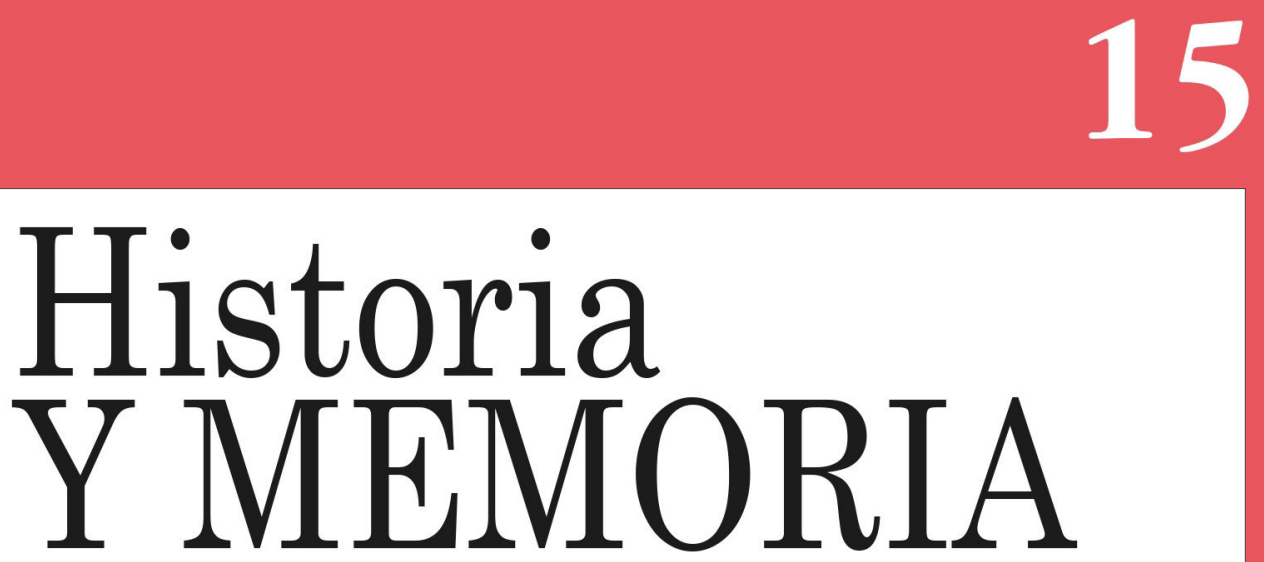

ISSN: 2027-5137 Julio - Diciembre, Año 2017 - Tunja, Colombia

Evangelización y occidentalización en la frontera sur del Reino de Chile. Los Franciscanos del Colegio de Misiones de Chillán, s. XVIII

https://doi.org/10.19053/20275137.n15.2017.5588

Cristián Leal Pino orcid.org/0000-0002-3797-4656

Andrés Quitral Manosalva orcid.org/0000-0002-8773-4255

Páginas: 139-168

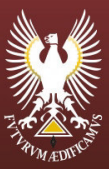




\title{
Evangelización y occidentalización en la frontera sur del Reino de Chile. Los Franciscanos del Colegio de Misiones de Chillán, s. XVIII*.
}

\author{
Cristián Leal Pino ${ }^{1}$ \\ Universidad del Bío Bío - Chile \\ Andrés Quitral Manosalva ${ }^{2}$ \\ Universidad Andrés Bello - Chile
}

Recepción: 28/07/2016

Evaluación: 26/05/2017

Aprobación: 05/06/2017

Artículo de Investigación e Innovación.

doi) https://doi.org/10.19053/20275137.n15.2017.5588

\section{Resumen}

El artículo se propone estudiar la participación del Colegio de Misiones de Chillán en la conquista espiritual de los indígenas, en la frontera sur del Reino de Chile hacia fines de la Colonia, con el propósito de analizar el rol que cumplieron los frailes

\footnotetext{
* $\quad$ El artículo es parte de los proyectos: Proyecto Regular DIUBB 152344/4R, 20152016: «La Orden franciscana en tiempos de la Independencia de Chile: Economía y política en los conventos de la Provincia Santísima Trinidad y el Colegio de Chillán», financiado por la Universidad del Bío Bío; y Proyecto Fondecyt No 11160795, 20172018: "Vida Conventual y formas de financiamiento de una orden mendicante en Chile: Los Franciscanos en el tránsito de la colonia a la república», financiado por Conicyt.

1 Doctor en Historia (Universidad Nacional de Cuyo - Argentina). Líneas de investigación: Historia Social, Historia Religiosa. Autor de "'Dejar de vivir en el siglo". La vida conventual de los frailes franciscanos en Chile, 1750-1850». Revista Historia 396 6, $\mathrm{n}^{\circ}$ 2, (2016): 369-397; y coautor de «Pobreza franciscana: entre utopía y realidad. La Provincia de la Santísima Trinidad hacia fines de la colonia en Chile» Memoria americana. Cuadernos de Etnohistoria, n² 24-1, (2016): 55-73. ه cleal@ ubiobio.cl (D) orcid.org/0000-0002-3797-4656

2 Licenciado en Historia. Investigador del grupo: «Academia de Estudios Religiosos de Chillán». Líneas de investigación: Historia local, Historia Colonial e Historia de Chile. Coautor de «El Colegio de Propaganda Fide de Chillán y el Hospicio de Santa Bárbara en la Evangelización de la Frontera Sur Andina del Reino de Chile: 17581766» Anuario de Historia de la Iglesia en Chile 32, (2014): 73-94. $ه$ an.quitral@ gmail.com (D) orcid.org/0000-0002-8773-4255
} 
seráficos en dicha época y lugar. Se utilizaron como fuentes de archivo los informes de misiones, reales órdenes, diarios de viaje, cartas, certificaciones y libros de cuentas existentes en el Archivo Nacional de Chile y el Archivo franciscano de Santiago de Chile. Con esta información se estableció el rol que cumplió el hospicio de Santa Bárbara y el Colegio de Naturales en la estrategia de evangelizar y occidentalizar al indígena. La hipótesis que planteamos es que los misioneros del Colegio de Chillán, hacia la segunda mitad del siglo XVIII, en la frontera sur del Reino de Chile, junto a la función espiritual, también cumplieron un rol político que, si bien no dio los frutos esperados por la Corona española, al menos contribuyó a generar espacios de comunicación entre las autoridades hispanocriollas y las parcialidades indígenas de la frontera.

Palabras Claves: Franciscanos, evangelización, occidentalización, colegio de Misiones Chillán.

\section{Evangelization and Westernization in the Southern Border of the Kingdom of Chile. The Franciscans of the Colegio de Misiones de Chillán [Mission School of Chillán], XVIII c.}

\section{Summary}

This article aims at studying the participation of the Mission School of Chillán in the spiritual conquest of the indigenous communities of the sourthern border of the Kingdom of Chile towards the end of the Colony. Its purpose is to analyze the role accomplished by Seraphic friars in this time and place. Archival sources examined were mission reports, royal orders, travel diaries, letters, certifications and account books in the National Archive of Santiago de Chile. This information enabled us to determine the role played by the Santa Barbara hospice and the School of Naturals in the strategies of evangelization and westernization of indigenous communities. The hypothesis proposed is that until the second half of the XVIII century, in the sourthern border of the Kingdom of Chile, the missionaries of the School of Chillán developed not 
only a spiritual, but also a political role. Even though this role did not harvest the expected results for the Spanish Crown, it succeeded in generating spaces of communication between the hispanic-criollo authorities and indigenous groups at the border.

Key Words: Franciscans, Evangelization, Westernization, Colegio de Misiones Chillán [Mission School of Chillán].

\section{Evangélisation et occidentalisation dans la frontière méridionale du Royaume du Chili. Les Franciscains du Collège de Missions de Chillan, XVIII ${ }^{\mathrm{e}}$ siècle}

\section{Résumé}

Cet article se propose d'étudier la participation du Collège de Missions de Chillan dans la conquête spirituelle des Indiens de la frontière méridionale du Royaume du Chili vers la fin de la période coloniale. Plus exactement, notre but est d'analyser le rôle des frères séraphiques dans ce processus et dans ces lieux précis. Nos sources sont constituées par des documents existant dans les Archives Nationales du Chili et dans les Archives franciscaines de Santiago du Chili: comptes rendus des missions, ordonnances royales, journaux de voyage, lettres, certificats et livres de comptabilité. A l'aide de ces informations nous avons établi le rôle joué par les hospices de Santa Bárbara et par le Collège des Indiens dans la stratégie d'évangéliser et d'occidentaliser l'indigène. Voici notre hypothèse : vers la deuxième moitié du XVIII ${ }^{e}$ siècle les missionnaires du Collège de Chillan, même s'ils n'ont pas été à la hauteur des attentes nourries par la Couronne espagnole, au moins ont contribué à générer des espaces de communication entre les autorités hispaniques et les groupes d'Indiens de la frontière.

Mots-clés: Franciscains, évangélisation, occidentalisation, Collège de Missions de Chillan. 


\section{Introducción}

La Orden franciscana en Chile ejerció su apostolado a través de dos ramas: la provincia de la Santísima Trinidad y la dependiente de la Congregación de Propaganda Fide, que heredó en el año 1767, las misiones dejadas por los jesuitas entre los indígenas de Chillán al sur ${ }^{3}$. Esta última institución fue creada por Gregorio XV en Roma, el año 1622, con la finalidad de «coordinar la actividad misionera de la Iglesia con especial atención a las grandes empresas de ultramar».

Al poco tiempo de su creación, recaería en la Orden franciscana la responsabilidad de llevar a cabo su organización. Así, en el marco de este nuevo instituto, nacerían al alero de los frailes seráficos los Colegios de Propaganda Fide, los que tendrían por misión reimpulsar el fervor misionero en la Orden, que habían iniciado en los comienzos de la conquista ${ }^{4}$.

Los Colegios «eran entidades autónomas, con estatutos propios y cuyo fin principal eran las misiones entre los infieles en un territorio determinado» ${ }^{5}$. De igual forma, debían brindar estabilidad y continuidad a las misiones, ser centros de instrucción de los misioneros y lugar de renovación física y espiritual de los religiosos ${ }^{6}$.

El precursor de los Colegios fue el padre Antonio Llinás, quien contó para ello con la aprobación del papa Inocencio XI y con el aval del monarca Carlos II, iniciándose en la segunda mitad del siglo XVII un «fecundo período de fundaciones de Colegios Apostólicos en España, de los cuales se nutrieron los Colegios americanos» ${ }^{7}$. En América, el proyecto se concretó el 18 de abril de 1682, cuando el rey Carlos II ordenó establecer

3 Gabriel Guarda, La Edad Media en Chile: Historia de la Iglesia desde la Fundación de Santiago a la incorporación de Chiloé, 1541-1826. (Santiago de Chile: Ediciones Universidad Católica, 2016), 185.

4 Guarda, La Edad Media en Chile..., 191.

5 Paulinna Etcheverry. Las Prefecturas Franciscanas de Misiones en Chile (Santiago de Chile: Publicaciones del Archivo Franciscano n 71 ), 9.

6 Paulinna Etcheverry. Las Prefecturas Franciscana, 9.

7 Beatriz Mallo, «El Itinerario Pastoral de Padre Juan Matud y la Fundación del Colegio Apostólico de San Carlos», Anuario de Historia de la Iglesia En Chile, $n^{\circ} 16$ (1998): 39. 
el Colegio de Querétaro en la Provincia de Michoacán, en el Virreinato de Nueva España, fundándose así el primer Colegio de Propaganda FIDE en América ${ }^{8}$.

El Colegio de Querétaro, tuvo la particularidad de desarrollar una formación especial para misioneros, mejorando el reclutamiento de los religiosos. Presentó, además, la novedad de que jurídicamente dependían de la Sacra Congregatio de Propaganda FIDE en Roma, por lo que la Corona Española no intervino directamente en el proceso que llevarían los misioneros en terreno, ni en las designaciones de las autoridades internas, a pesar de recibir subvención por parte de esta última. En lo apostólico, los Colegios dependían de la Congregación de Propaganda Fide; y en lo propiamente franciscano, directamente del Comisario General de Indias o del Comisario General de Misiones; y en lo económico, directamente del Rey ${ }^{9}$.

En Chile, durante el siglo XVIII tomó fuerza la idea de los Colegios de misiones, que luego de varios intentos fallidos, se estableció el primero de ellos en la ciudad de Chillán en el año 1756. Si bien su existencia no ha concitado del todo el interés de los historiadores, es importante conocer más en detalle el cómo se involucró en la política de la Corona Española durante la segunda mitad del siglo XVIII. Por ello, pretendemos determinar el rol que jugó en la frontera sur del Reino de Chile, centrándonos en el Hospicio de Santa Bárbara y el Colegio de Naturales, como instituciones claves en el proceso de evangelización.

La hipótesis que planteamos es que los misioneros del Colegio de Chillán, hacia la segunda mitad del siglo XVIII, en la frontera sur del Reino de Chile, junto a la función espiritual también cumplieron un rol político que, si bien no dio los

8 Maynard Gaiger, "The Malllorcar Contribution to Franciscan California», The Americas 4 (1947): 141-142, URL: https://www.jstor.org/stable/977966 acceso 9 de abril de 2016.

9 Rigoberto Iturriaga, «Fray Domingo Gonzáles. Algunos sucesos acaecidos a los misioneros de Chillán después de la migración (1817-1835)», Anuario de Historia de la Iglesia en Chile, ${ }^{\circ} 14$ (1996): 60. 
frutos esperados por la Corona española, al menos contribuyó a generar espacios de comunicación entre las autoridades hispanocriollas y las parcialidades indígenas de la frontera.

El análisis se hizo a partir de la consulta de fuentes documentales existentes en el Archivo Nacional y Archivo Franciscano de Santiago de Chile. Se trabajó con el Catálogo Jesuita de América, los expedientes de aprobación de las cuentas de gastos del colegio seminario de Naturales de Chillán, fondo Contaduría Mayor y los formularios de libros de cuenta del Seminario de Naturales de Chillán. En primer lugar, se clasificó la correspondencia entre el Discretorio del Colegio de Misiones y la gobernación del Reino de Chile. En segundo lugar, se seleccionó la información que tuviera relación directa con el Hospicio de Santa Bárbara y el Colegio de Naturales. Luego ser procedió a la triangulación de las fuentes y a la interpretación socio-cultural de la información. Finalmente, el análisis estuvo centrado en el contexto evangelizador y político, permitiéndonos explorar las condiciones políticoculturales de los relatos consultados en los documentos.

\section{Los fundamentos para la evangelización del Reino de Chile.}

La llegada del mundo cristiano a los confines más australes de América del Sur estuvo marcada por la férrea resistencia de los indígenas a subordinarse a los conquistadores hispanos. Las constantes rebeliones y destrucción de ciudades, presente durante el proceso de conquista del Reino de Chile, logró interiorizarse en la conformación de las relaciones políticas que ponían en juego la soberanía hispana en estas latitudes. En primer lugar, es importante destacar la función de la Iglesia Católica en la consolidación del dominio hispano sobre los territorios al norte del río Bío-Bío. En segundo lugar, destacar el valor de las órdenes religiosas en la tarea de evangelizar y civilizar a los indígenas, las cuales establecieron las bases para el asentamiento de una política donde primaran las relaciones diplomáticas por sobre las acciones militares. 
Esto se puede apreciar, por ejemplo, en la discusión dentro del mundo cristiano sobre la libertad de los indios de guerra. El desastre de Curalaba en el año 1598, que tuvo, entre otras consecuencias, la muerte del gobernador Oñez de Loyola y la promulgación de la Real Cédula del 26 de mayo de 1608 por Felipe III, que propiciaba un escenario idílico para la esclavitud de los indios cogidos en guerra ${ }^{10}$. La lógica hispana para la esclavitud de los indígenas se fundamentaba en que los indios antes de la llegada de los españoles vivían como infieles, situación que cambió con la llegada de los cristianos, quienes convirtieron a los indios según el encargo pontificio. En consecuencia, por haber aceptado la fe, los indígenas se convertían en apóstatas cuando se rebelaban al español ${ }^{11}$. Uno de los argumentos se puede apreciar en las siguientes líneas:

[...] efte titulo el Rey en nomre de la Iglefia les haze jufta guerra, quando no huuiera prouabilidad en lo demás, y fi tanto amauan fu libertad beftialmente, no fe baptizaran ningu dellos, ni tan poco auia dexar baptizar a los niños, pero pues ya fe baptizaron, y apoftataron, aunque mas derecho tengan a no fujetarfe al Rey, no le tienen los baptizados a no fujetarfe a la Iglesia, y entregarles los hijos della, que lo fon mas hijos nueftros que fuyos $[\ldots]^{12}$.

Este argumento, muy cuestionado por los frailes de las Órdenes religiosas, permitió el surgimiento de ácidas críticas sobre el estado de la comprensión de la fe por parte de los indios en la frontera del Reino. El Jesuita Diego de Rosales, principal detractor de la esclavitud, acusaba a la soldadesca de sus crímenes y crueldades con los indios, diciendo:

[...] obran, pensando hacer obsequio a su Rey, contra su gusto y voluntad, por ser contra la del Rey del cielo, con quien siempre se conforman los reyes de la tierra, como tan católicos y justificados, que aunque quieren que los gentiles se les sujeten a su obediencia para embiarles predicadores y ministros que les prediquen el Santo Evangelio, y con

10 Guarda, La Edad Media en Chile..., 83.

11 Walter Hanisch, «Esclavitud y Libertad de los Indios de Chile, 1608-1696». Revista Historia, (1981): 22.

12 Melchor Calderon, Tratado de la Importancia y Vtilidad Que Ay En Dar Por Efclauos a Los Indios Rebelados de Chile. (Madrid: 1607), 205-206. 
ese cargo le dio Sumo Pontifice a nuestro Rey el dominio de las Indias, no es su voluntad que entren sus soldados en las Provincias de las Indias haciéndoles guerra a fuego y sangre y pasando a los indios a cuchillo para ponerles temor $\mathrm{y}$ haciéndolos esclavos sin haverlos primero requerido y ofrecíendoles buen tratamiento de parte de su Rey ${ }^{13}$.

Rosales, acusaba que los soldados se entrometían y hacían uso de la fuerza sin mérito alguno, en virtud de su beneficio personal por sobre las cuestiones de la enseñanza del evangelio. El religioso señalaba:

La maior dificultad es: si se podrá hacer guerra a los indios infieles y hacerlos esclabos por sus delitos, y porque vengan a ser christianos y vivir en la ley de Dios sacarlos de sus tierras, donde viven como bestias; porque los soldados, pareciéndoles que hacen obsequio a Dios y al Rey, y lo mas cierto por interes de los esclabos y tener que vender, los maloquean sin ser enemigos, los queman las cassas y quitan la libertad, diciendo que es mejor que sean esclabos que no vivan en sus vicios ${ }^{14}$.

Durante la primera mitad del siglo XVII, la situación política del Reino de Chile estuvo marcada por diversas corrientes de pensamiento. Unos participaban de la Real Cédula de 1608, otros justificaban una guerra defensiva en la frontera del Bío-Bío, a raíz del ambiente de agitación propiciado por los indios rebeldes. En este último aspecto, es importante destacar la participación de eclesiásticos en establecer relaciones dentro del mundo indígena, donde también estuvieron involucrados los obispos de Concepción.

En este contexto, la misión Jesuita adquirió importancia durante los siglos coloniales, sobre todo en las zonas más alejadas y periféricas del imperio hispano, como lo fue el caso del Obispado de Concepción ${ }^{15}$. De los primeros misioneros jesuitas que llegaron al Reino de Chile, fue Luis de Valdivia

13 Diego de Rosales, Historia General de El Reyno de Chile, Flandes Indiano, tomo I (Valparaíso: Imprenta del Mercurio, 1877), 449.

14 Rosales, Historia General de El Reyno de Chile..., 451.

15 José Gabriel Martínez-Serna, «Los Jesuitas y el desarrollo económico de la frontera sur del imperio hispánico, siglos XVI-XVIII», en La Frontera en el Mundo Hispánico, ed. Porfirio Sanz y David Rex (Quito: Abya-Yala, 2014), 382. 
uno de los más destacados, quien ayudó a convencer a las autoridades civiles de un cambio en la estrategia fronteriza tras la derrota de Curalaba, para reemplazar la encomienda y la guerra ofensiva por la defensiva y la evangelización de los indígenas. De esta forma, la misión en la Araucanía comenzó a ser importante para la pacificación de la zona durante el siglo XVII. Sin embargo, no faltaron los detractores, como el gobernador Alonso de Ribera, quién desechó la estrategia del padre Valdivia, producto de la hostilidad mapuche en la frontera y las diferencias entre los jesuitas y el gobernador ${ }^{16}$.

Avanzando en el siglo XVII, con las "Paces de Quilin», en el año 1641, se afianzan las negociaciones y la diplomacia en la política fronteriza hispano-mapuche ${ }^{17}$, donde la misión tendría un espacio de acción muy importante, pasando a ser la estrategia más apropiada para introducir el cristianismo y pacificar a los indígenas. De estos encuentros saldrán acuerdos, como el siguiente:

Primeramente an de oyr la doctrina christiana y enseñanza de la fee catholica con toda reverençia a los religiosos que fueren a este efecto y quando les paressiere están catequisados como combiene an de rezivir el sancto bauptismo a los niños y niñas de menor hedad se an de bauptisar luego con gustos de sus padres y los an de llevar o ymbiar oyr la Doctrina siempre que fueren llamados (...) A lo qual respondieron por dicho ynterprete que lo admiten y que su desseo es tener padres que los doctrinen $[\ldots]^{18}$.

Por medio del parlamento ${ }^{19}$, la misión comienza a incorporarse en las relaciones hispano-mapuches, como

16 Martínez-Serna, «Los Jesuitas y el desarrollo económico...», 383.

17 Zavala, Los Parlamentos Hispano-Mapuches, 1593-1803: Textos Fundamentales (Temuco: Universidad Católica de Temuco, 2014), 18.

18 Zavala, Los Parlamentos Hispano Mapuches, 130.

19 El Parlamento es una institución interétnica, que se gestó en Chile durante el siglo XVI, consolidándose en el siglo XVII. Se genera a partir del contacto entre las dos tradiciones diplomáticas: la hispana y Mapuche. Ver, Gertrudis Payàs Puigarnau, José Manuel Zavala Cepeda y Ramón Curivil Paillavil, «La Palabra 'Parlamento' y su Equivalente en Mapudungun en los Ámbitos Colonial y Republicano: Un Estudio sobre Fuentes Chilenas Bilingües y de Traducción», Historia 47, nº 2 (2014): 360-61, DOI: dx.doi.org/10.4067/S0717-71942014000200003; además, Sergio Villalobos y Jorge Pinto (coords.), Araucanía: temas de Historia fronteriza, (Temuco: 1985); Pablo 
condicionante de los acuerdos de paz al interior de las parcialidades indígenas en la frontera del Bíobio. En este sentido, destacamos lo señalado por el etnohistoriador Boccara, a raíz de la transculturación de los reche-mapuche, ejecutada mediante el empleo de dos diagramas, en los cuales circulan los dispositivos de poder aplicados en la política "fronteriza»: El primero, llamado diagrama soberano, contiene elementos concretos de poder, tales como: el requerimiento, la encomienda, la expedición de conquista, la esclavitud, la maloca y el fuerte. El segundo, más presente durante el siglo XVIII, es un diagrama disciplinario que se materializa con un dispositivo de poder como la misión, el parlamento, el comercio, la escuela de indios, caciques gobernadores, etcétera ${ }^{20}$. Carlos Contreras Painemal, sitúa esta propuesta de Boccara, señalando que el etnónimo adecuado para denominar a los indígenas de Chile es de reche, posteriormente araucanos, en la misma línea que el historiador Sergio Villalobos, quien ha sido prácticamente el más ferviente defensor de esta propuesta, que según Contreras Painemal es confusa y tiene su origen en el poema épico La Araucana de Alonso de Ercilla ${ }^{21}$. Diego Rosales los denomina como indios aucas, y los misioneros del Colegio de Chillán, lograban diferenciar los vutanmapu e incluían en su lenguaje etnónimo de Peguenches ${ }^{22}$, Gentes de la Tierra, Picunches, etcétera.

En el contexto en que se desarrolló el proceso para la evangelización en el Reino de Chile, el historiador Goicovich, argumenta que fue el fin al régimen esclavista (1683) el hecho

Mariman., ed., Parlamento y territorio mapuche, (Temuco: Editorial Escaparate, 2008); y Tom Dillehay y José Manuel Zavala «Compromised Landscapes: The ProtoPanoptic of Colonial Araucanian and Spanish Parlamentos», Colonial Latin American Review 22, $\mathrm{n}^{\circ} 3$, (2013): 320-342.

20 Guillaume Boccara, «Notas acerca de los dispositivos de poder en la sociedad colonial-fronteriza, la resistencia y la transculturación de los reche-mapuches del Centro-Sur de Chile (XVI-XVIII)», Revista de Indias 56, nº 208 (1996): 674-675, DOI: dx.doi.org/10.3989/revindias.1996.i208.803.

21 Carlos Contreras Painemal, «Los Tratados celebrados por los Mapuche con la Corona Española, la República de Chile y la República de Argentina», (Freie Universität Berlín, 2011), 35. http://d-nb.info/1026265320/34.

22 Miguel de Ascasubi, Informe Cronológico de las Misiones del Reino de Chile hasta 1789, (Santiago de Chile: Publicaciones del Archivo Franciscano n 49, 1997), 29 . 
que tuvo mayor relevancia para pasar a una nueva época, en que la política evangelizadora se desplegó y consolidó en la Araucanía ${ }^{23}$. De esta forma, la misión se configuró como un instrumento privilegiado de vigilancia y disciplina de los indios. Bajo una estricta planificación civil y eclesiástica, se buscó desplazar al indígena, reducirlo y apropiarse de su tiempo. El misionero ejercitaba poder sobre los cuerpos y sobre los quehaceres de los indios ${ }^{24}$.

La misión fue consolidándose como estrategia política, con el fin de reproducir diálogos interétnicos, penetrar en los modos de vida y costumbres de "los indios de tierra adentro» para transformarlos a los intereses de la Iglesia y la Corona. Sobre esto último, Jorge Pinto, nos señala que la predicación del evangelio y conversión de la Araucanía comenzó a ser prioridad para la Corona después de $1655^{25}$. Además, que los misioneros actuaron en plena libertad, desarrollando un modelo de contacto con los indígenas no-violentado, con dos tendencias en las relaciones con los indígenas. El primero, dentro del discurso formal de los misioneros, marcado por expresiones etnocentristas y etnocidas. El segundo, en el marco del discurso informal (que es de suma relevancia), encontramos a los misioneros como humanos conviviendo cotidianamente con los indígenas, dispuestos a transar y a comprender una cultura que para ellos era ajena ${ }^{26}$.

De esta forma, las Órdenes religiosas, como la Compañía de Jesús y los misioneros franciscanos del Colegio de Chillán, adquirieron gran importancia en el proceso político de expansión cultural, sobre todo en la administración de los Borbones, la que buscó cambiar el sistema de dominación e instaurar una máquina civilizadora que funcionó mediante la inculcación e interiorización de nuevas normas en las

23 Francis Goicovich, «Entre conquista y consolidación fronteriza: Dispositivos de poder Hispánico en los Bosques Meridionales del Reino de Chile durante la etapa de transición (1598-1683)». HISTORIA II, n 40 (2007): 325.

24 Boccara, «Notas acerca de los dispositivos de poder...», 675.

25 Jorge Pinto, «Etnocentrismo y Etnocidio. Franciscanos y Jesuitas en La Araucanía, 1600-1900», CUHSO (1991), 37-70.

26 Jorge Pinto, «Etnocentrismo y Etnocidio...», 47. 
costumbres de los indígenas, por medio de la propagación de la fe católica ${ }^{27}$.

Para la política fronteriza del Reino de Chile, tanto el parlamento como la misión de los «infieles», funcionaban como un dispositivo arquetípico de un nuevo modelo de poder que se instaló desde la segunda mitad del siglo XVII hasta fines del siglo XVIII ${ }^{28}$. En este último momento, el Colegio de misiones de Chillán, se afianzó como la institución que las gestionó, es decir, fue la encargada de diseñar instrumentos de vigilancia y disciplina en parcialidades indígenas, para educar a los «infieles».

\section{El hospicio de Santa Bárbara como enclave misionero en la frontera sur del Reino de Chile}

La misión franciscana contó con la participación de las autoridades civiles del Reino de Chile, la cual se reflejó en la planificación de la evangelización en tierras Pehuenches. Lo anterior, se puede apreciar en la preparación de la construcción del hospicio de Santa Bárbara ${ }^{29}$, institución que se gestó en el Parlamento del Salto del Laja, el mismo año de la fundación del Colegio de misiones de Chillán el año 1756.

El hospicio de Santa Bárbara fue donado por el Gobernador Manuel Amat y Juniet a los misioneros de Chillán ${ }^{30}$. La estrategia consistió en demarcar un sitio para la construcción del hospicio en las cercanías del fuerte de Santa Bárbara para las entradas de misioneros hacia la otra banda del río Biobío. La principal función del hospicio, fue dar resguardo a los misioneros que estuvieran establecidos «tierra

27 Guillaume Boccara, «El poder creador: tipos de poder y estrategias de sujeción en la frontera sur de Chile en la época colonial», Anuario de Estudios Americanos 1, tomo LVI (1999): 68, DOI: dx.doi.org/10.3989/aeamer.1999.v56.i1.288.

28 Boccara, "Notas acerca de los dispositivos...», 682-689.

29 El hospicio fue el lugar de acogida, mantención y educación para los hijos de los caciques. Desde allí se desplegarían una serie de misiones en tierras de infieles. Distinto a lo que se entendía por hospicio en la estructura de la Provincia franciscana de la Santísima Trinidad, que lo reducía a un convento pequeño de menos de doce frailes.

30 Ascasubi, Informe Cronológico de las Misiones..., 29. 
adentro». Sobre el lugar, el franciscano Miguel de Ascasubi señalaba:

Esta situado cerca del fuerte y villa de Santa Bárbara á los 36 gs y $37 \mathrm{~ms}$ de latitud austral, con corta diferencia, al pié de la cordillera y á la márgen del Biobio por la parte del norte, tan inmediato á los infieles de la espresada nación, que entre ellos y el hospicio solo media el cajón del rio [... $]^{31}$.

El hospicio de Santa Bárbara fue un intento de consolidar el poder real en un punto fronterizo y, además, la conformación de una villa para establecer un centro urbano en el sector cordillerano, como parte de la política de expansión y afianzamiento imperial de la Corona en zonas periféricas del Reino, lo que constituyó una muestra clara del abandono de la estrategia de los asentamientos militares. Lo anterior, lo podemos apreciar en el siguiente texto sobre la donación del sitio a los misioneros de Chillán para la instauración del hospicio de Santa Bárbara:

[...] dicho combento, mirando asia la parte de la cordillera con ochenta varas de frente y una quadra, y ocho varas de fondo, considerando por suficiente este ámbito para la edificación de la Iglesia, y demás ofizinas prezissan: en cuia atención mando (...) se hiziesse una cruz, y se juntasen para el dia siguiente todos los vecinos pobladores, eclasiasticos, oficiales de tropa, y demás personas para proceder con la formalidad devida $[\ldots]^{32}$.

La donación del sitio, para la construcción del hospicio de Santa Bárbara, se llevó a cabo el 29 de noviembre de 1758, con la solemnidad característica del protocolo hispánico, en la idea de generar lazos simbólicos, mediante la gracia divina $^{33}$. En las palabras del Gobernador del Reino de Chile,

31 Ascasubi, Informe Cronológico de las Misiones..., 29.

32 «Adjudicación echa por el Señor Capitán Gobernador del Reino para la fundación del Hospicio de Santa Bárbara», 1758, Archivo Franciscano Santiago de Chile (AFSCh). Santiago-Chile, Colegio de Chillán (CCh), Asuntos Varios (AV), vol. 1, f. 94vl.

33 Jaime Valenzuela Márquez, Las Liturgias del Poder: Celebraciones públicas persuasivas en Chile Colonial (Santiago: Ediciones de la Dirección de bibliotecas, Archivos y Museos, 2001), 213. 
al momento de materializar la donación del sitio, es posible observar lo antes dicho:

[...] haviendo llegado al sitio determinado, se cantó la oración de la Santa Cruz, e incensada, la coxió su alteza el señor Presidente en las manos, y levantándola, la depositó en el nicho prevenido, y en voz alta pronuncio delante de todos el concursso que va referido estas palabras: en nombre del Rey mi señor que Dios Guarde y en virtud de las facultades que en mi residen como su gobernador y capitán general de este reino hago donación del terreno marcado a los citados missioneros de nuestro Padre San Francisco para que erijen combento e Iglesia en el, con el titulo de la Santa Cruz, reservado, como reservo todo el derecho del Real Patronato $[. . .]^{34}$.

El carácter público y la expectación que tuvo la construcción del hospicio de Santa Bárbara, adquiere importancia toda vez que pensamos en la comprensión de las relaciones cívico-eclesiásticas en la planificación de la evangelización. De esta forma, se establecieron dos dinámicas importantes: El poder del Estado Borbón (o del Rey) y su legitimización en puntos territoriales estratégicos para la dominación cívico-religiosa. En este sentido, el discurso de la fe, la educación y cristianización de los infantes desde el Hospicio de Santa Bárbara ${ }^{35}$, sería el primer paso para la occidentalización del vuthamapu cordillerano.

Tras el acto protocolar de entrega del sitio para la construcción del hospicio, los misioneros franciscanos comienzan oficialmente a ejecutar su labor evangelizadora. El día 4 de diciembre de 1758, el Teniente de Caballería, Comandante y Juez de la villa de Santa Bárbara, Juan Segundo López, daría aviso de la llegada de dos misioneros provenientes del Colegio de Chillán, más dos religiosos legos, quienes habrían cruzado a la otra banda del Bío-Bío, en un lugar llamado Rucalhue, para iniciar las negociaciones con ülmenes, Pehuenche de la parcialidad mencionada. Los sucesos que allí ocurrieron se pueden apreciar en las siguientes líneas:

34 "Adjudicación echa por el Señor Capitán Gobernador del Reino para la fundación del Hospicio de Santa Bárbara», 1758, AFSCh, Santiago-Chile. CCh, AV, vol. 1, ff. 95vl.-96.

35 Ascasubi, «Informe cronológico de las Misiones...», 30. 
Al paraje que nombran Rucalhue, therreno que habitan, infieles de la nación peguenche (...) zitaron a Junta particular de la que resulto prometer dichos infieles, sujetarse al yugo de Nuestra Santa Ley, por cuya causa resolvieron dichos reverendos padres como consta de autos que ante mi se siguieron el día nueve del mencionado mes y año, quedarse dos a fabricar Iglesia y combentito, en dho paraje de Rucalhue que fueron el padre fray Juan de San Antonio, con otro compañero oficial y sirvientes $[\ldots]^{36}$.

Desde antes que concluyera completamente la edificación del hospicio de Santa Bárbara, los misioneros del Colegio de Chillán, comenzaron a planificar el establecimiento de reducciones en las cercanías de Santa Bárbara. Juan Segundo López, ofrece más detalles sobre lo ocurrido en el paraje de Rucalhue, donde es posible constatar que concurrieron los ülmenes de la parcialidad y de otros lugares cercanos, entre mocetones, mujeres y niños ${ }^{37}$. Allí se dispuso:

[...] los caziques entre si respondieron unanimes: que desde luego nos recivian y azetavan todo lo propuesto como también lo havia ofrezido al señor Presidente en la Villa de Santa Barvara y que asi destinaremos en aquel paraxe el sitio que mejor nos pareciese para Iglesia y abitacion competente a cuya construcción concurrirían asalariados su mozetones sin ser necesario otros peones estraños (...) habiendo labrado una alta Cruz y gravado en ella esta inscripción en señal de nuestro establecimiento año de mil septecientos cinquenta y ocho la coxieron a hombros los mismos infieles y con los demás concursantes se formo una prozesion con Salmos, Letanias e hignos propios de el asumto ${ }^{38}$.

La misión de Rucalhue, fue la primera reducción que los misioneros franciscanos del Colegio de Chillán realizaron en tierras de «infieles» en Chile. Pedro Ángel de Espiñeira y Juan de San Antonio, al ser recibido por los ülmenes Pehuenche, determinaron inmediatamente el sitio para establecer la

36 «Certificacion del combento de la Villa de Santa Bárbara del dia a su mandato travaxar los Reverendos Padres en la fundación de Rucalhue», 1758, AFSCh, Santiago-Chile. CCh, $A V$, vol. 1, f. 98.

37 "Testimonio de haver concedido sitio para fundar el hospicio de Santa Barbara», 1758, AFSCh, Santiago-Chile. CCh, $A V$, vol. 1, f. 101vl.

38 AFSCh «Testimonio de haver concedido sitio para fundar el hospicio de Santa Barbara», f. 101vl. 
iglesia y una vivienda para acoger a los misioneros que se establecerían en la misión. El lugar se encontraba a dos leguas de la villa de Santa Bárbara.

Se destinaron 500 pesos de sínodo (dinero público) para su construcción, la cual se concluyó en abril de 1759 . Los misioneros destinados a la misión fueron: Francisco Sánchez y Juan de San Antonio. Sin embargo, Pedro Ángel de Espiñeira (quien sería más tarde obispo de Concepción) regresó al Colegio de Chillán, para partir a la banda oriental de los Andes a fines de diciembre de 1758, donde se reunió con los principales ülmenes de esa parcialidad, para fundar la segunda misión de Rarinleuvu ${ }^{39}$.

El hospicio de Santa Bárbara finalizó su edificación el 24 de Junio de $1760^{40}$, lo que vino a cambiar en algún sentido la organización interna del Colegio de misiones de Chillán, ya que se nombró presidente del hospicio a Francisco Sánchez y Procurador de las misiones a Juan de San Antonio, quienes debieron establecer su estadía oficial en Santa Bárbara ${ }^{41}$. Ambos recibían 150 pesos de sínodo, más los 500 pesos anuales para la manutención del hospicio ${ }^{42}$.

También, funcionó el hospicio como centro educacional al que los principales ülmenes entregaron sus hijos para que recibieran instrucción, que consistía principalmente en el aprender castellano, leer, contar, cantar y ayudar en las misas a los religiosos ${ }^{43}$. Sobre el particular, un documento de 1760 hace referencia a la entrega de un niño indígena para que ingrese al hospicio:

39 Archivo Nacional de Chile (ANCH), Santiago-Chile, «Misiones entre los indios Pehuenches», ff. 1-58.

40 «Christiana Muerte del Cacique de Rucalhue Don Christoval Pichipillan», 1760, AFSCh, Santiago-Chile. CCh, $A V$, vol. 1, f. 153.

41 «Copia del Informe que hizo al señor presidente de este Reino de Chile», 1762, AFSCh, CCh, $A V$, vol. 1, f. 345 .

42 AFSCh, «Copia del Informe que hizo al señor presidente de este Reino de Chile», f. $344 \mathrm{vl}$.

43 AFSCh, «Copia del Informe que hizo al señor presidente de este Reino de Chile», f. 345 . 
[...] bino a este ospicio o combento de Santa Cruz de Santa Barbara, cabeza de misiones el cazique y Capitan de su parcioalidad Don Christoval Pichipillan con su única mujer, acompañado de algunos de sus indios a fin solo de entregarnos para la instrucción catholica un hijo de diez a 12 años el que asta ahora se mantiene en nuestra compañía con singular aplicación a los rudimientos de nuestra santa fee y no quedándole otro hijo de fineza digna de atención (después trajo otro muchacho para compañía del otro) $[\ldots]^{44}$.

La entrega del hijo de Pichipillan (ülmen de Quilaco), para que los misioneros franciscanos lo educaran en el Hospicio, fue sin duda un voto de confianza a raíz de las experiencias pasadas. Cuando ingresaron los misioneros por primera vez a Rucalhue, el mismo Pichipillan creía que los religiosos venían a quitarle los hijos para llevarlos a España ${ }^{45}$.

Este proceso de generar confianzas no estuvo exento de resistencias al interior de las parcialidades. El 12 de marzo de 1760 la reducción y misión de Rucalhue fue totalmente quemada, las sospechas vinculaban a Curiman (otro ülmen de la misión), sin embargo, tanto Pichipillán como Curiman culparon a «indios de los llanos» ${ }^{46}$. Esta noticia fue corroborada por el misionero Juan de San Antonio, en la que da cuenta de una riña entre algunos Pehuenches y «llanistas», resultando que estos últimos quemaron la iglesia ${ }^{47}$.

El hecho fue grave por sus costos, ya que para la misión de Rucalhue se destinaron 500 pesos para la edificación de la capilla, oficinas y habitación de dos misioneros, de los cuales se entregaron 150 pesos anuales para cada uno. Sin embargo, el proyecto no fue puesto en duda, como lo podemos apreciar en un documento enviado por el rey Carlos III, quien ofrecía más apoyo en la labor misional de los frailes del Colegio de Chillán. El documento señalaba lo siguiente:

44 AFSCh, «Christiana Muerte del Cacique de Rucalhue Don Christoval Pichipillan», f. 153.

45 AFSCh, «Christiana Muerte del Cacique de Rucalhue Don Christoval Pichipillan», f. 154.

46 «Relación de la quema de Rucalhue», 1760, AFSCh, Santiago-Chile. CCh, $A V$, vol. 1, f. 150vl.

47 AFSCh, «Relación de la quema de Rucalhue», f. 151. 
Del establecimiento de quatro misiones, que os pidieron los Indios Peguenche, y de los Llanos expresado averse exigido para los primeros en los sitios nombrados Rerinleubu y Rucalhue; (...) y os mando que para qualquiera otra misión, que se haya establecido en este medio tiempo, o se estableciese en adelante destinereis, vos la cantidad, con que se haya de conbenir asi para los referidos gastos, y avio de misioneros como para el sínodo anual de estos $[\ldots]^{48}$.

Tiempo después, se estableció la reducción de Quilaco, construida en remplazo de la anterior (que fue quemada) y, finalmente, la reducción de Lolco en el Alto Biobío en 1766, igualmente quemada en el levantamiento indígena del mismo año.

\section{El Colegio de Naturales: La insistencia en una estrategia evangelizadora y occidentalizadora.}

El Colegio de Naturales, fue una institución que estuvo destinada a la cristianización y occidentalización de hijos de los caciques traídos desde la Araucanía ${ }^{49}$. Los primeros antecedentes para establecer un Colegio de Naturales en Chile, los encontramos en la Cédula enviada por el rey Carlos II, con fecha 11 de mayo de 1697, donde ordena la fundación de un Colegio bajo el arbitrio de la Compañía de Jesús en Chillán ${ }^{50}$. Para ello se destinó una renta anual de 280 pesos al rector, de 240 pesos para los profesores y una pensión de 120 pesos para cada uno de los dieciséis hijos de caciques que debían vivir en el establecimiento ${ }^{51}$. Pese a la cédula del Rey, quien ordenaba financiar el Colegio de Naturales mediante recursos del Real Situado, desde Lima rechazaron destinar los recursos para los «caciquitos de Chillán» ${ }^{52}$.

48 «Real Cédula aprobando lo ejecutado en el establecimiento de varias misiones que pidieron los indios Pehuenches», 1761, ANCH, Santiago-Chile. CG, vol. 723, ff. 231[212], 231vl.[212vl.]

49 Jaime Valenzuela Márquez, Fiesta, Rito y Política: del Chile Borbónico al Republicano (Santiago: Ediciones de la Dirección de bibliotecas, Archivos y Museos, 2014), 109.

50 Reinaldo Muñoz Olave, Historia de Chillán (Santiago: Andujar, 1997), 109.

51 Muñoz Olave, Historia..., 109.

52 Muñoz Olave, Historia..., 113-114, 
En septiembre del año 1700, el Colegio comienza a funcionar con las limosnas de los chillanejos y de los ingresos obtenidos de la hacienda de $\mathrm{Cato}^{53}$, que era trabajada por indios guambalí traídos desde Concepción, a raíz de la política de traspasos de población, que las autoridades de la villa penquista habían establecido a fines del siglo XVII ${ }^{54}$.

El año de 1723, los religiosos de la Compañía de Jesús comenzaron su empresa para construir una iglesia "para la educación y enseñanza de los hijos de vecinos de dicha ciudad y de los caciques que ha mandado su majestad ${ }^{55}$. El Colegio de Naturales se mantuvo hasta 1723 , cerrando producto del conflicto bélico que trajo el levantamiento indígena del mismo año. Debemos destacar la responsabilidad que tuvieron los superiores de la Compañía de Jesús por llevar a cabo esta empresa y el compromiso de las autoridades locales por mantenerla. Los religiosos ignacianos habían tenido importantes logros en la predicación del evangelio, ejercicios espirituales, confesiones y comuniones, con «las dos escuelas de Christo, de hombres y mujeres y de niños e hijos de los casiques de la tierra» ${ }^{56}$.

Luego de unas décadas de interregno, el Colegio de Naturales reabrió sus puertas en la ciudad de Santiago el año 1775. Ahora, el tutelaje de los hijos de los caciques quedó en manos del clero secular de la capital del Reino. Para esta segunda experiencia, el historiador Jaime Valenzuela, señala que el Colegio tenía el propósito de cristianizar y occidentalizar a los hijos de caciques, con la finalidad de que una vez devueltos a sus comunidades, fuesen los nuevos jefes que ejercieran las influencias para cambiar «desde el interior» y "desde arriba» su cultura ${ }^{57}$. En el aspecto cívico,

53 Walter Hanisch, Historia de la Compañia de Jesús en Chile (Buenos Aires: Editorial Francisco de Aguirre, 1974), 56.

54 Jorge Pinto e Iván Inostroza, Expansión capitalista y economía mapuche: 16801930 (Temuco: Ediciones Universidad de la Frontera, 2014), 27-31.

55 «Decreto para la erección de la iglesia» 1713, ANCH, Santiago-Chile. Catálogo Jesuitas de América (CJA), Provincia Chilena (PCh), vol. 94, f. 4.

56 «En la ciudad de San Bartolomé de Chillán del Reyno de Chile» 1713, ANCH, Santiago-Chile. CJA, PCh, vol. 94, f. 9.

57 Valenzuela Márquez, Fiesta, Rito y Política..., 51. 
los colegiales debieron participar corporativamente en las principales celebraciones públicas, se les asignó un espacio específico, donde se presentaban con un traje similar a los colegiales hispanos: Con su hopa parda, chupa y beca (color verde desde el año 1778$)^{58}$, en la que destacaba el distintivo de una corona y el nombre de Carlos III ${ }^{59}$.

El costo de mantener el Colegio de Naturales, siempre fue un dilema. Entre 1777-1785 se habían gastado alrededor de 32.802 pesos, cifra no menor para una institución pequeña. El excesivo gasto, la lejanía del lugar de origen de los estudiantes, fueron minando la idea de mantenerlos en Santiago. Además, existía meridiana claridad del ahorro que significaba trasladar el Colegio a Chillán ${ }^{60}$. Sobre esto último, una carta emitida desde el Colegio de misiones en el año 1776, da cuenta de una temprana solicitud, realizada por el Gobernador de aquel entonces, Agustín Jáuregui, para que los misioneros apostólicos de Chillán se hicieran cargo de dicha institución ${ }^{61}$.

Esta petición fue rechazada por los prelados del Colegio de misiones, ya que se negaron a asumir los costos de la construcción de un nuevo Colegio de Naturales. Las gestiones del traslado quedaron en pausa. Sin embargo, el regente de la Real Audiencia, Tomás Albarez Acevedo, reanudaría las acciones para trasladar el Colegio a Chillán en el año $1785^{62}$. La respuesta fue la siguiente:

En orden a si subsistimos en el pensamiento de aceptar la aplicación destino del colegio de los Jesuitas para la enseñanza de Indios Jóvenes que se extrajesen de los infieles (...) debo decir a Vuestra Señoría que no solo subsistimos en

\footnotetext{
58 Alejandro Fuenzalida Escandón, Historia del desarrollo intelectual de Chile (Santiago: Imprenta Universitaria, 1903), 247.

59 Valenzuela Márquez, Fiesta, Rito y Política..., 51.

60 Roberto Lagos, Historia de las misiones del Colegio de Chillán, (Barcelona: Ediciones Herederis Juan Gil, 1908), 314-315.

61 «Respuesta del Discretorio a la del señor Presidente de Chile», 1776, AFSCh, Santiago-Chile. CCh, AV, vol. 4, f. 15

62 «Al R. P. guardián del Colegio de Propaganda Fide», 1785, AFSCh, SantiagoChile. CCh, AV, vol. 5, f. 154.
} 
el mismo pensamiento pero tenemos aun los mas vivos deseos de que se sertifique la dicha aplicación por parecernos mui conducente a la pacificacion, y cibilización de los Naturales, a la subsisitencia, y aumento de nuestras misiones (...) todos los indios celebraran mucha la fundación de un Colegio de Naturales en esta ciudad sobre lo cual me hablaron repetidas vezes los caziques $[\ldots]^{63}$.

En el documento, podemos destacar tres puntos de interés. En primer lugar, los términos de "pacificación» y "civilización», que ya eran utilizados por las autoridades civiles y eclesiásticas, siendo este tipo de lenguaje clave para comprender el desarrollo y la ejecución de la política que llevaron a cabo los misioneros de Chillán. En el segundo punto, encontramos una estrategia que alcanzó una doble funcionalidad: Evangelizar y enseñar costumbres, hábitos y moral occidental. De los logros obtenidos por el Colegio de Naturales de Santiago antes de su traslado a Chillán, Alejandro Fuenzalida expresa:

El presidente Benavides, en mayo 27 de ese año, permitió que siete de esos estudiantes mudaran de carrera: a tres para "amanuenses en algún estudio i oficina de pluma», a tres en "oficios de sastres» i al sétimo de carpitenro, los que fueron colocados por su ex-rector don Agustín Escandón, i ausiliados con dos reales cada uno, mientras se hacían bien aptos para ganarse la vida. En 1788 dos de esos estudiantes cambiaban de ocupación haciéndose el uno barbero i el otro músico $[\ldots]^{64}$.

Por lo general, los colegiados preferían aprender oficios más que optar por el camino al sacerdocio. La existencia del Colegio no estuvo exenta de problemas, especialmente cuando se producían los traslados, así ocurrió cuando debieron partir a Chillán. En ese entonces, los estudiantes mayores de edad en el Colegio eran: Pascual Reuquiante, José María Guenupichun, Ignacio Tabalaquen, José María Painepichun, Juan Bautista Anicoyan, Francisco Quiñelicon; y los menores,

63 «Informe del Guardián al Gobernador sobre establecimiento de Seminario de Naturales», 1785, AFSCh, Santiago-Chile. CCh, AV, vol. 5, ff. 156-157.

64 Fuenzalida Grandón, Historia del desarrollo..., 240. 
Martín Erice y Pedro y Pablo Reuquiante ${ }^{65}$, donde el mayor no sobrepasaba los 12 años de edad. De estos últimos, la madre de los hermanos Reuquiante y la abuela de Martín Erice, se opusieron al traslado de estos niños a Chillán, sin embargo, luego de una serie de negociaciones accedieron a su traslado ${ }^{66}$.

La reducción de costos finalmente, fue la causa de trasladar el Colegio de Naturales nuevamente a Chillán, pero ahora bajo la administración de los franciscanos. Las ventajas estaban a la vista: Se ahorrarían dinero (el no pago de Rector y profesores), la formación intelectual y experiencia en terreno de los frailes seráficos y la cercanía con la frontera, lo que ofrecía mayores facilidades a los ülmenes para visitar a sus hijos.

Finalmente, el Gobernador Ambrosio Benavides, envió un oficio al guardián del Colegio de misiones para efectuar el traslado de los colegiales. Allí expresaba:

Por el adjunto testimonio era Vuestro Padre Reverendo mi última providencia sobre hacer efectiva la trasladación del Colegio de Naturales a esa cuidad que verifica caminando al cuidado del Reverendo Padre Presidente de ese convento Fray Blas Alonso los diez alumnos y Beca que existían en esta capital; y contando con este número podra Vuestro Padre Reverendo admitir los correspondientes hasta el completo de veinte que se podrán solicitar por medio de los religiosos de su instituto $[\ldots]^{67}$.

Alejandro Fuenzalida, en una transcripción de los documentos sobre nóminas de estudiantes que ingresaron a la facultad de filosofía de la Universidad de San Felipe el año 1794, incorpora una lista oficial llamada «estudiantes de diversas facultades que cursan las aulas de este Convento Grande de predicadores» ${ }^{68}$. Para estudiantes de primer año, en el curso de

65 Fuenzalida Grandón, Historia del desarrollo..., 241.

66 «Estado de los gastos del Colegio de Naturales de Chillán» 1786, ANCH, Santiago-Chile. CJA, $P C h$, vol. 22, ff. 60-62.

67 «Testimonio del Decreto de la Capitanía General sobre el traslado del seminario», AFSCh, Santiago-Chile. CCh, $A V$, vol. 5, f. 214.

68 Alejandro Fuenzalida Grandón. La Evolución Social en Chile (1541-1810), (Santiago: Imprenta Litografía i Encuadernación Barcelona, 1906), 281. 
teología de Melchor Cano, figuran en la lista «Dr. D. Pascual Reuqueante» y «Dr. D. Juan Baptista Anicoyan» ${ }^{69}$. Gabriel Guarda, nos da noticias del pequeño Martín de Erice, quien en 1797 se matricula en la Universidad de San Felipe en medicina y rinde su último examen de filosofía en $1801^{70}$.

El número de hijos de caciques que pasaron por el Colegio de Naturales entre 1775-1811 fue de 68, y, de ellos, solo una minoría abrazó el sacerdocio. Los demás accedieron a los oficios comunes de la época, como relojero, carpintero, pintor, escribano, barbero o sastre. Mientras que Francisco Inalicán y Francisco Millapichún, fueron de los pocos que decidieron pertenecer a la Orden de San Francisco ${ }^{71}$.

Para el año 1813, se produjeron dos ceremonias de investidura, la de Juan Calbugur y Pedro Quinchaguala. El primero se convirtió en sacerdote, y el segundo, en relojero (son seguramente los últimos graduados de la experiencia educativa llamada Colegio de Naturales que se tiene registro). Para su investidura se necesitó de tela de Bretaña, zapatos, charretelas, sombreros finos, pañuelos, pantalón, casaca, etcétera ${ }^{72}$. Todo ello implicó un gasto superior a los $380 \operatorname{pesos}^{73}$. Este último dato, deja en claro la relevancia de la vestimenta dentro de la cotidianidad urbana de la ciudad colonial, considerando que esta representó el estatus que el colegiado iba a tener dentro de la sociedad hispana. Era la vestimenta, una forma de control y vigilancia de los espacios cotidianos e indicadores de los estatus socio-étnicos y económicos de los individuos ${ }^{74}$.

69 Fuenzalida Grandón, Evolución Social..., 281.

70 Gabriel Guarda, La Sociedad en Chile Austral antes de la Colonización Alemana 1645-1845 (Santiago: Andres Bello, 1979), 28.

71 Karin Pereira, «Del Colegio al Seminario de Naturales: Los franciscanos y la educación indígena en Chile, 1786-1811», en Los Franciscanos en Chile: Una historia de 450 años, ed. René Millar y Horacio Aránguiz. (Santiago de Chile: Academia chilena de la Historia, 2005), 183-185.

72 «Presupuesto del vestuario que necesitan los dos indios alumnos del Colegio de Chillán D. ${ }^{\mathrm{n}}$ Juan Calbugur y D. ${ }^{\mathrm{n}}$ Pedro Quinchaguala», 1813, ANCH, Santiago-Chile. CJA, $P C h$, vol. 89, f. 323.

73 ANCH, «Presupuesto del vestuario...», f. 323.

74 Cecilia Moreyra, «Entre lo íntimo y lo público: la vestimenta en la ciudad de Córdoba a fines del siglo XVIII», en Fronteras de la Historia 15, nº 2 (2010): 394. 
A partir de la segunda mitad del siglo XVIII, las autoridades civiles del Reino se concentraron en la planificación de estrategias para pacificar a los indígenas de la frontera sur mediante la instauración de instituciones que se hicieran cargo de la educación de los hijos de caciques. Fue a partir de las políticas borbónicas, cuando se costeó y se dispuso una importante cantidad de dinero para el mantenimiento del Colegio de Naturales. Podríamos decir que, a partir de la segunda mitad del siglo XVIII, se comenzó a consolidar una política en la frontera que estuvo más destinada a la occidentalización que a la enseñanza del cristianismo propiamente tal. Por lo general, parte de la historiografía tradicional de Chile, tienden a suponer que el gasto de 40 años de funcionamiento, fue un despilfarro de dinero y que la estrategia civilizadora fue un rotundo fracaso:

En suma, los esfuerzos de los padres franciscanos para dar a los hijos de indígenas habían fracasado miserablemente (...) a la gran masa de esos educados, no se les habían estirpado sus hábitos nativos, i al regresar al país de sus mayores volvían a la vida bárbara cual si nunca hubieran conocido la civilizada. Este resultado de la educación de los seminarios para indígenas sirve a la vez, para medir el harto más efímero que se logró con las misiones, que por lo mismo de ser breves e intermitentes dejaban al bárbaro en la condición primitiva, cuando no agravada por vicios peores $[\ldots]^{75}$.

Tomando en cuenta la reflexión anterior, podemos preguntarnos: ¿fue un fracaso o una consolidación la estrategia civilizadora que ejecutaron los misioneros del Colegio de Chillán en la frontera sur del Reino de Chile? Desde nuestro punto de vista, podemos decir que sería injusto concluir que la estrategia fue un fracaso, basándonos solo en gastos, los altos costos materiales y los resultados poco visibles, de esta política civilizadora y pacificadora que aplicó la Corona española.

Además, destacamos que es de importancia, valorar los aspectos socioculturales y el contexto político en que se ejecutó esta estrategia en el proceso imperial de expansión cultural. Esto último, nos ayuda a tener una visión más

$\overline{75}$ Fuenzalida Grandón, Historia del Desarrollo..., 47-248. 
clara de las estructuras y las relaciones político-culturales, diplomáticas y educativas, que se desarrollaron en el Reino de Chile, particularmente, después de la segunda mitad del siglo XVIII. Lo relevante, fue el interés del gobierno borbón de invertir en educación, destinada a los «hijos de caciques» para lograr una integración no-violentada a la sociedad colonial. Si bien, compartimos en algunos aspectos, que el proyecto educativo que implementaron los franciscanos hacia la cultura Pehuenche y de la Araucanía, siempre estuvieron bajo los juicios etnocentristas de los misioneros, que apuntaron a la extirpación de las costumbres y hábitos al interior de los vuthamapus, consideramos que es necesario reconocer $\mathrm{y}$ destacar el valor que tuvieron estos métodos, los que fueron, sin dudarlo, menos violentos y mucho más conciliadores, en comparación a los que se aplicaron en los albores de la conquista.

\section{Conclusiones}

El Colegio de misiones de Chillán estuvo al servicio de la política de la Corona Española en la frontera sur del Reino de Chile, la que tuvo como propósito integrar las parcialidades Pehuenche y de la Araucanía a la sociedad colonial. Los misioneros del Colegio de Chillán, a partir de la segunda mitad del siglo XVIII, se transforman en los principales ejecutores de esta empresa. En este sentido, observamos dos instituciones que se alinearon con la política de la Corona, como el hospicio de Santa Bárbara, ubicada en la banda norte del río Bío-Bío y aledaño a las parcialidades Pehuenches; y el Colegio de Naturales, que estuvo bajo la administración de los franciscanos entre 1786-1811.

El hospicio de Santa Bárbara fue también una institución destinada a la enseñanza del cristianismo, donde las autoridades civiles del Reino y los frailes seráficos acogen a los «hijos de caciques», en un lugar políticamente estratégico, de penetración hacia el sector cordillerano. No en vano, el hospicio de Santa Bárbara fue considerado como un lugar «cabecera» para las misiones en tierras Pehuenches. 
Por otro lado, el Colegio de Naturales, a cargo de los frailes seráficos en Chillán, tuvo también un rol estratégico en la pacificación y occidentalización del indígena. Esto es posible observar no solo en su planes de estudios, ni en la prohibición de hablar en su lengua nativa, lo que ha sido estudiado por Karin Pereira ${ }^{76}$, sino que también, y como lo hemos establecido en el texto, en las vestimentas de los estudiantes y en las ceremonias de investiduras, al momento de recibir las sagradas órdenes o un oficio.

De esta forma se desarrolló una relación directa del poder civil local, con las "autoridades» eclesiásticas que convivieron con los «indígenas» ultra Biobío, ratificando la existencia de una estructura política y diplomática, que se desarrolló mediante la propagación de la fe católica entre los «infieles» aledaños y tradicionalmente hostiles en el Reino de Chile.

Finalmente, y a partir de la hipótesis trabajada, es necesario preguntarse si en estos encuentros entre las autoridades hispanocriollas y las parcialidades indígenas de la frontera se terminó con la violencia de los siglos anteriores. Pensar en las acciones emprendidas por el colegio de Misiones de Chillán, concretamente en el Colegio de Naturales, en las prohibiciones que tenían los hijos de los caciques, como el no hablar en su idioma nativo y vestirse a la usanza occidental, constituyen o no una forma de violencia. Es sin duda una línea interesante de seguir profundizando.

\section{Fuentes de Archivo}

Archivo Nacional de Chile (ANCH), Santiago-Chile. Capitanía General, vol, 723 .

ANCH, Santiago-Chile. Catálogo Jesuitas de América (CJA), Provincia Chilena (PCh), vol. 22.

ANCH, Santiago-Chile. CJA, PCh, vol. 89.

76 Pereira, Karin. El Real Colegio de Naturales. (Santiago de Chile: Publicaciones del Archivo Franciscano n $\left.{ }^{\circ} 73,2002\right)$. 
ANCH, Santiago-Chile. CJA Provincia Chilena (PCh), vol. 94.

Archivo Franciscano Santiago de Chile (AFSCh), Santiago-Chile. Colegio de Chillán (CCh), Asuntos Varios (AV), vol. 1, ff. 94-97.

Archivo Franciscano de Santiago de Chile, Santiago-Chile. CCh, $A V$, vol. 1, ff. 98-98vl.

AFSCh, Santiago-Chile. CCh, $A V$, vol. 1, ff. 101-103vl.

AFSCh, Santiago-Chile. CCh, $A V$, vol. 1, ff. 150-152vl.

AFSCh, Santiago-Chile. CCh, $A V$, vol. 1, ff. 153-155vl.

AFSCh, Santiago-Chile. CCh, $A V$, vol. 1, ff. 341-354vl.

AFSCh, Santiago-Chile. CCh, $A V$, vol. 4, ff. 15-16.

AFSCh, Santiago-Chile. CCh, $A V$, vol. 5, ff. 154.

AFSCh, Santiago-Chile. CCh, $A V$, vol. 5, ff. 156-157.

AFSCh, Santiago-Chile. CCh, $A V$, vol. 5, f. 214.

\section{Bibliografía}

Ascasubi, Miguel de. Informe Cronológico de las Misiones del Reino de Chile hasta 1789. Santiago de Chile: Publicaciones del Archivo Franciscano n ${ }^{\circ}$ 49, 1997.

Boccara, Guillaume. «Notas acerca de los dispositivos de poder en la Sociedad Colonial-Fronteriza, la resistencia y la transculturación de los Reche-Mapuches del Centro-Sur de Chile (XVI-XVIII)». Revista de Indias 56, nº 208 (1996): 65995.

Boccara, Guillaume. «El poder creador: tipos de poder y estrategias de sujeción en la frontera sur de Chile en la época colonial». Anuario de Estudios Americanos 1, tomo LVI (1999): 65-94. DOI: dx.doi.org/10.3989/aeamer.1999.v56.i1.288. 
Calderón, Melchor. Tratado de la Importancia y Vtilidad Que Ay En Dar Por Efclauos a los Indios Rebelados de Chile. Madrid, 1607.

Contreras Painemal, Carlos. "Los Tratados celebrados por los Mapuche con la Corona Española, la República de Chile y la República de Argentina.» Freie Universität Berlin, 2011. http://d-nb.info/1026265320/34.

Dillehay, Tom., y Zavala, José Manuel. «Compromised Landscapes: The Proto-Panoptic of Colonial Araucanian and Spanish Parlamentos». Colonial Latin American Review 22, $\mathrm{n}^{\circ} 3$ (2013): 320-342.

Etcheverry, Paulinna. Las Prefecturas Franciscanas de Misiones en Chile. Santiago de Chile: Publicaciones del Archivo Franciscano n ${ }^{\circ} 71,2002$.

Fuenzalida Grandón, Alejandro. Historia del desarrollo intelectual de Chile. Santiago: Imprenta Universitaria, 1903.

Fuenzalida Grandón, Alejandro. La Evolución Social en Chile (1541-1810). Santiago: Imprenta Litografía i Encuadernación Barcelona, 1906.

Gaiger, Maynard. «The Mallorcar Contribution to Franciscan California». The Americas 4 (1947): 141-50.

Goicovich, Francis. «Entre Conquista y Consolidación Fronteriza: Dispositivos de Poder Hispánico en los Bosques Meridionales del Reino de Chile durante la etapa de Transición (15981683)». HISTORIA II, n 40 (2007): 311-32.

Guarda, Gabriel. La Edad Media en Chile: Historia de la Iglesia desde la Fundación de Santiago a la incorporación de Chiloé, 1541-1826. Santiago de Chile: Ediciones Universidad Católica, 2016.

Guarda, Gabriel. La Sociedad en Chile Austral antes de la Colonización Alemana 1645-1845. Andres Bello, 1979.

Hanisch, Walter. «Esclavitud y Libertad de los Indios de Chile, 1608-1696». Revista Historia, 1981. 
Hanisch, Walter. Historia de la Compañía de Jesús en Chile. Buenos Aires: Editorial Francisco de Aguirre, 1974.

Iturriaga, Rigoberto. «Fray Domingo Gonzáles. Algunos sucesos acaecidos a los Misioneros de Chillán después de la migración (1817-1835).» Anuario de Historia de La Iglesia En Chile, $\mathrm{n}^{\circ}$ 14 (1996).

Lagos, Roberto. Historia de las Misiones del Colegio de Chillán. 1908th ed. Barcelona: Ediciones Herederis Juan Gil, 1908.

Mariman, Pablo., ed. Parlamento y territorio mapuche, Temuco: Editorial Escaparate, 2008.

Mallo, Beatriz. «El Itinerario Pastoral de Padre Juan Matud y la Fundación del Colegio Apostólico de San Carlos». Anuario de La Historia de La Iglesia En Chile, n 16 (1998): 39-56.

Martínez-Serna, José Gabriel. «Los Jesuitas y el desarrollo económico de la Frontera Sur del Imperio Hispánico, Siglos XVI-XVIII». En La Frontera en el Mundo Hispánico, coordinado por Porfirio Sanz Camañes y David Rex Galindo, 371-398. QuitoEcuador: Abya-Yala, 2014. https://onedrive.live.com/redir?re sid=7AD7F82A56F02D86!597\&authkey=!AJeKqqXlBco4RBs \&ithint $=$ file $\% 2$ cpdf.

Moreyra, Cecilia. «Entre lo íntimo y lo público: La vestimenta en la ciudad de Córdoba a fines del siglo XVIII». Fronteras de la Historia 15, nº 2 (2010): 388-413.

Muñoz Olave, Reinaldo. Historia de Chillán. Santiago: ANDUJAR, 1997.

Payàs Puigarnau, Gertrudis., José Manuel Zavala Cepeda, y Ramón Curivil Paillavil. «La Palabra 'Parlamento' y su Equivalente en Mapudungun en los Ámbitos Colonial y Republicano: Un Estudio Sobre Fuentes Chilenas Bilingües y de Traducción». Historia 47, $\mathrm{n}^{\circ} 2$ (2014): 360-61, DOI: dx.doi.org/10.4067/ S0717-71942014000200003

Pereira, Karin. El Real Colegio de Naturales. Santiago de Chile: Publicaciones del Archivo Franciscano nº 73, 2002. 
Pereira, Karin. «Del Colegio al Seminario de Naturales: Los franciscanos y la educación indígena en Chile, 1786-1811». En Los Franciscanos en Chile: Una historia de 450 años, editado por René Millar y Horacio Aránguiz, 171-186. Santiago de Chile: Academia chilena de la Historia, 2005.

Pinto, Jorge. «Etnocentrismo y Etnocidio. Franciscanos y Jesuitas en la Araucanía, 1600-1900». CUHSO (1991): 37-70.

Pinto, Jorge., e Iván Inostroza. Expansión capitalista y economía mapuche: 1680-1930. Temuco: Ediciones Universidad de la Frontera, 2014.

Rosales, Diego de. Historia General de El Reyno de Chile, Flandes Indiano. Tomo I. Valparaíso: Imprenta del Mercurio, 1877.

Valenzuela Márquez, Jaime. Fiesta, Rito y Política: Del Chile Borbónico al Republicano. Santiago: Ediciones de la Dirección de bibliotecas, Archivos y Museos, 2014.

Valenzuela Márquez, Jaime. Las Liturgias del Poder: Celebraciones públicas persuasivas en Chile Colonial (1606-1709). Centro de Investigaciones Diego Barros Arana. Santiago: Ediciones de la Dirección de bibliotecas, Archivos y Museos, 2001.

Villalobos, Sergio., y Jorge Pinto, coords. Araucanía: temas de Historia fronteriza, Temuco, 1985.

Zavala, José Manuel. «Parlamento de Quilin de 1647, AGI, Chile, 21, Fs. 1-16vl.» En Los Parlamentos Hispáno-Mapuches, 15931803: Textos Fundamentales, 123-34. Temuco: Universidad Católica de Temuco Ediciones, 2015.

\section{Citar este artículo:}

Leal Pino, Cristián., y Andrés Quitral Manosalva. «Evangelización y occidentalización en la frontera sur del Reino de Chile. Los Franciscanos del Colegio de Misiones de Chillán, s. XVIII». Historia Y MEMORIA, n 15 (2017): 139168. DOI: https://doi.org/10.19053/20275137.n15.2017.5588 